\title{
HUBUNGAN PAPARAN WHOLE BODY VIBRATION DAN MASA KERJA DENGAN PENURUNAN KETAJAMAN PENGLIHATAN PENGEMUDI PADA PO NIKKO PUTRA DI KOTA YOGYAKARTA
}

\author{
Andi Wibowo', Widodo Hariyono ${ }^{1}$, Kentari Septiasih ${ }^{2}$ \\ ${ }_{1}^{1}$ Fakultas Kesehatan Masyarakat, Universitas Ahmad Dahlan, Yogyakarta \\ ${ }^{2}$ Balai Hyperkes dan Keselamatan Kerja Daerah Istimewa Yogyakarta
}

\begin{abstract}
PO Nikko Putra is a bus company which serves Yogyakarta - Tempel route. The condition of bus machine which have old and lack of maintenance will cause high exposure a whole body vibration felt by the driver. The long exposure whole body vibration will generate health troubles, one of them degradation of visus. This research is aimed to know the correlation whole body vibration and working time with visus degradation of the driver. This research is conducted observasionally with cross sectional design. Research population are 55 people and the sample obtained is 26 people which meet the inclusion criterion.

Exopusure whole body vibration suffered by driver is $1.257 \mathrm{~m} / \mathrm{s}^{2}$ presence during 11 hours in one day, according to ISO 2631 included in category exopusure limit. The result of correlation analysis on Pearson coefficient of exposure whole body vibration and visus for right eye with $p$ 0.981 and the left eye $p$ 0.592, hence Ho is accepted because the $p$ value $>0.05$. Whereas, the analysis on the working time with degradation of right eye visus with $p 0.709$ and the left eye with $p$ 0.990 , hence $\mathrm{Ho}$ is accepted because probability value $>0.05$. This research conclude that there is no correlation whole body vibration and working time with degradation of visus that the driver.
\end{abstract}

Keyword: driver, whole body vibration and visus

\section{PENDAHULUAN}

Transportasi selama ini mempunyai peran yang sangat penting dan strategis dalam pembangunan serta dalam memperlancarkan roda perekonomian suatu negara. Pentingnya sarana transportasi terlihat pada semakin meningkatnya kebutuhan jasa angkutan untuk mobilitas orang maupun barang dari satu daerah ke daerah lain, baik lewat darat, air, dan udara, sehingga kelancaran transportasi dan dampaknya akan secara langsung dapat dirasakan oleh masyarakat.

Transportasi darat merupakan salah satu sektor teknologi yang terus mengalami perkembangan. Hal ini dapat dilihat dari jumlah dan jenis kendaraan yang semakin banyak dan arus lalu lintas yang semakin padat. Inovasi dalam bidang ini berjalan terus-menerus seiring dengan kebutuhan manusia akan daya jangkau dan jelajah yang semakin besar. Akan tetapi di sisi lain, apabila tidak ditangani dengan baik teknologi ini dapat berubah menjadi mesin pembunuh yang sangat berbahaya. ${ }^{1}$

Salah satu faktor fisik lingkungan kerja pengemudi yang dapat mengakibatkan penyakit akibat kerja pada sarana transportasi darat berupa bis adalah paparan getaran mekanis yang berasal mesin bis. Getaran ini memapari seluruh tubuh pekerja, sehingga disebut dengan whole body vibration. Keputusan Menteri Tenaga Kerja No. 51/Menaker/1999 menyatakan tentang Nilai Ambang Batas Faktor Fisik di Tempat Kerja, getaran mekanis adalah gerakan yang teratur dari benda atau sebuah media dengan arah bolak-balik dari kedudukan keseimbangan. ${ }^{2}$ Getaran dibedakan menjadi dua macam, yaitu: (1) hand arm vibration atau getaran tangan dan lengan, pada 
umumnya dihubungkan dengan penggunaan dalam pekakas tangan yang bergetar, dan (2) whole body vibration atau getaran seluruh tubuh, pada umumnya dialami oleh supir atau operator yang duduk pada suatu mesin yang bergetar seperti sarana angkutan yang digunakan di pertanian, transportasi, pertambangan, dan kehutanan (Joubert, 2001). ${ }^{3}$

Paparan whole body vibration ini juga dialami oleh pengemudi bis PO Nikko Putra Yogyakarta. Suma'mur $(1988)^{4}$ menyatakan bahwa whole body vibration dapat menyebabkan efek fisiologis seperti mempengaruhi peredaran darah, gangguan saraf, menurunkan ketajaman penglihatan, kelainan pada otot, dan tulang. Paparan whole body vibration ditransmisikan ke tubuh pengemudi melalui tempat duduk. Berdasarkan hasil wawancara dengan pengemudi, menunjukkan adanya gangguan penglihatan seperti keluhan kelelahan mata setelah seharian mengemudikan bis.

Gangguan akibat paparan whole body vibration pada pengemudi dapat menimbulkan kerugian bagi pengemudi itu sendiri. Oleh karena itu gangguan tersebut harus segera dicegah untuk menghindari kecelakaan dan penyakit akibat kerja serta meningkatkan produktivitas kerja, sehinga pekerja dapat melakukan aktivitasnya dalam keadaan selamat dan sehat. Tujuan penelitian ini untuk mengetahui hubungan paparan whole body vibration dan masa kerja dengan penurunan ketajaman penglihatan pengemudi bis PO Nikko Putra Yogyakarta.

\section{METODE PENELITIAN}

Penelitian ini merupakan penelitian observasional dengan rancangan cross sectional karena mengamati status penyakit secara serentak pada individu-individu dari suatu populasi pada satu saat (Murti, 1996) $\square .^{5}$ Rancangan penelitian cross sectional dipilih karena rancangan ini sangat sesuai dengan penelitian yang akan dilaksanakan dan mengamati faktor risiko (paparan whole body vibration) dan efek (penurunan ketajaman penglihatan) dalam satu waktu.

\section{A. Populasi dan Sampel}

Lokasi penelitian dilakukan di PO Nikko Putra Yogyakarta dengan alasan perusahaan tersebut merupakan perusahaan otobis trayek Yogyakarta - Tempel yang banyak memiliki aramada bis dan pengemudi. Populasi penelitian ini adalah seluruh pengemudi bis (beroperasi) yang bekerja di PO Nikko Putra Yogyakarata yang berjumlah 55 orang dan di dapat sampel sebesar 26 pengemudi. Penentuan sampel penelitian dengan menggunakan kriteria inklusi sebagai berikut:

1) Bersedia dijadikan subjek penelitian.

2) Berusia kurang dari 40 tahun.

3) Tidak mempunyai kelainan pada mata dan tidak menggunakan kaca mata minus, plus atau slindris.

4) Tidak sedang sakit mata.

5) Sedang bekerja saat penelitian

\section{B. Alat Penelitian}

1) Untuk Mengukur Variabel Bebas

Untuk mengukur whole body vibration digunakan vibration meter merek Rion VM-83 buatan Jepang yang telah dikalibrasi. Cara kerja dari peralatan:

a) Kabel bnc dimasukkan ke stop kontak meter bnc.

b) Kabel mini dimasukkan ke stop kontak sensor vibrasi. 
c) Untuk mengukur akselerasi tombol acceleration/velocity dipilih pada posisi acc. Untuk pengukuran velocity tombol vel ditekan.

d) Tombol $\mathrm{rms} /$ peak ditekan pada posisi $\mathrm{rms}$.

e) Untuk mengaktifkan alat ukur tersebut tombol power ditekan satu kali. Jika permukaan objek diukur tidak mengandung bahan-bahan dari besi, diambil sensor vibrasi dan ditempelkan pada permukaan objek.

f) Frekuensi vibration meter dipilih sesuai dengan kebutuhan pengukuran.

g) Untuk mengukur besarnya peak, tombol rms dipilih, peak pada posisi peak. Selama pengukuran monitor akan menunjukan nilai peak.

h) Selama pengukuran tombol hold ditekan dan akan menyimpan hasil pengukuran sehingga lcd akan menunjukan simbol $d h$. Tombol hold ditekan kembali untuk menghentikan fungsinya.

i) Data record fungsinya untuk menunjukan rata-rata pengukuran maksimum dan minimum. Untuk mengaktifkannya, tombol record ditekan, simbol rec akan tampak pada monitor $l c d$.

j) Simbol rec akan menunjukan:

1) Nilai maksimal jika tombol recall ditekan.

2) Tombol recall ditekan kembali untuk menunjukan nilai minimal.

3) Tombol record ditekan untuk menghentikan fungsinya.

Standar atau nilai ambang batas tingkat getaran whole body vibration yang berlaku di tingkat internasional mengacu pada ISO 2361 tentang getaran untuk kenyamanan dan kesehatan pekerja, dengan klasifikasi sebagai berikut:

Kurang dari $0,315 \mathrm{~m} / \mathrm{dt}^{2}$

a) $0,315-0,630 \mathrm{~m} / \mathrm{dt}^{2}$

b) $0,630-1,000 \mathrm{~m} / \mathrm{dt}^{2}$

c) $1,000-1,600 \mathrm{~m} / \mathrm{dt}^{2}$

d) $1,600-2,000 \mathrm{~m} / \mathrm{dt}^{2}$

e) Lebih dari $2,000 \mathrm{~m} / \mathrm{dt}^{2}$
: nyaman.

: sedikit kurang nyaman.

: agak tidak nyaman.

: tidak nyaman.

: sangat tidak nyaman.

: sangat tidak nyaman ekstrim.

Masa kerja adalah lama seorang pengemudi PO Nikko Putra Yogyakarta yang di hitung dari pengemudi tersebut mulai bekerja di PO Nikko Putra Yogyakarta sampai dilakukannya penelitian ini. Data masa kerja pengemudi diperoleh melalui pengisian formulir data.

\section{Untuk Mengukur Variabel Terikat}

Guyton $(1994)^{6}$ menyatakan bahwa Optotype Snellen merupakan suatu alat klinis untuk mengukur ketajaman penglihatan jauh seseorang. Biasanya huruf yang telah baku pada Optotype Snellen untuk memeriksa ketajaman penglihatan di tempatkan pada jarak 5 atau 6 meter $\square$ tergantung jenis dan ukuran Optotype Snellen yang digunakan di depan orang yang akan di uji, dan jika orang tersebut dapat melihat huruf dengan ukuran baku yang harus dilihatnya dari jarak 6 meter, dikatakan bahwa ia mempunyai ketajaman penglihatan 6/6 yaitu ketajaman penglihatan normal. Jika ia hanya dapat melihat huruf-huruf yang seharusnya dapat dilihatnya pada jarak 60 meter, dikatakan bahwa ia mempunyai ketajaman penglihtan 6/60.

Penelitian ini dalam mengukur tingkat ketajaman penglihatan pada pengemudi bis menggunakan Optotype Snellen. Setiap mata diperiksa terpisah. Ketajaman penglihatan mata kanan terlebih dahulu kemudian mata kiri lalu dicatat. 
Pemeriksaan ketajaman penglihatan jauh dengan menggunakan Optotype Snellen yang dilakukan dengan prosedur sebagai berikut:

a) Pemeriksaan dilakukan pada jarak 6 meter disesuaikan dengan ukuran Optotype Snellen yang digunakan $\square$ pengukuran jarak menggunakan meteran gulung $\square$.

b) Pengemudi diminta untuk menututup mata kiri dengan telapak tangannya, tanpa ditekan lalu diminta melihat ke arah Optotype Snellen dengan santai, tanpa melirik atau mengerutkan kelopak matanya.

c) Pengemudi diminta untuk membaca huruf pada Optotype Snellen sampai baris terkecil yang masih dapat terbaca. Bila pengemudi hanya dapat mengenali huruf pada baris yang menunjukkan angka 6 , berarti ketajaman penglihatan pengemudi adalah $6 / 6$ dan begitu seterusnya jika pengemudi hanya dapat melihat huruf yang menunjukkan angka 30, berarti ketajaman penglihatan pengemudi adalah 30/6. Setelah itu lalu diperiksa ketajaman penglihatan mata sebelah kiri pengemudi dengan prosedur yang sama seperti pemeriksaan ketajaman penglihatan mata kanan.

d) Apabila tidak dapat membaca huruf terbesar pada Optotype Snellen, maka dilakukan uji hitung jari.

e) Pengemudi diminta untuk menghitung jari mulai dari jarak 1 meter, kemudian semakin mundurlah hingga jarak terjauh yang dapat dilihat oleh pengemudi.

\section{HASIL PENELITIAN DAN PEMBAHASAN}

\section{A. Gambaran Umum Perusahaan}

Perusahaan Otobis (PO) Nikko Putra Yogyakarta merupakan salah satu dari beberapa perusahaan milik swasta yang bergerak dalam bidang transportasi Angkutan Kota Dalam Propinsi (AKDP) trayek Yogyakarta - Tempel. Perusahaan ini merupakan gabungan dari beberapa pengusaha bis trayek Yogyakarta Tempel yang tidak mempunyai ijin operasi trayek dan didirikan oleh seorang pengusaha bis yang bernama Susanto pada tahun 1998. Pada waktu pertama kali berdirinya, armada yang dimiliki berjumlah 100 unit bis dengan jumlah pengemudi dan kernet kurang lebih 200 orang. Selanjutnya pada tahun 2003 perusahaan mengalami penurunan pendapatan dan sempat berhenti sejenak kemudian perusahaan ini dibeli oleh Sudarno lalu lokasi perusahaan pindah di Ngawen 02/11 Trianggo Gamping Sleman dan sekarang pindah lagi ke Depokan II Kranggan No. 182 Kota Gede Yogyakarta dengan alasan dekat dengan Terminal Bis Yogyakarta

Perkembangan PO Nikko Putra sampai sekarang memiliki armada sebanyak 76 armada bis dengan pengemudi dan kernet kurang lebih 148 orang sedangkan armada yang beroperasi hanya 55 armada bis. Penurunan jumlah armada bis dikarenakan banyak pengusaha yang tergabung dalam PO Nikko Putra yang tidak mampu membiayai operasional bis yang melonjak tajam, sedangkan penghasilan yang didapat tidak dapat menutupi biaya yang sudah dikeluarkan sehingga banyak pengusaha yang gulung tikar dan beralih profesi. Bahkan ada sebagian pengemudi yang menonaktifkan kernetnya dikarenakan penurunan penghasilan.

\section{B. Karakteristik Subyek Penelitian}

KES MAS Vol. 5, No. 3, September $2011: 162-232$ 
1) Distribusi Usia dan Masa Kerja Pengemudi PO Nikko Putra Yogyakarta

Rata-rata usia subyek penelitian 35 tahun, usia paling tua adalah 40 tahun dan usia paling muda adalah 26 tahun. Rata-rata masa kerja pengemudi ialah 9 tahun, masa kerja paling lama adalah 20 tahun dan masa kerja paling muda adalah 2 tahun. Usia pengemudi yang dijadikan subyek dibatasi dengan usia maksimal 40 tahun dikarenakan pada usia di atas 40 tahun tubuh manusia mengalami penurunan dengan seiring bertambahnya usia, baik dari segi fisik dan metabolisme tubuh. Suma'mur $(1988)^{4}$ jarang sekali ditemukan ketajaman penglihatan normal pada pekerja yang berusia diatas 40 tahun.

2) Distribusi Usia Bis, Merek Bis dan Paparan Whole Body Vibration yang Diterima Pengemudi Bis PO Nikko Putra Yogyakarta

Rata-rata usia bis yang digunakan oleh subyek adalah 19 tahun, usia bis paling tua adalah 26 tahun dan usia bis paling muda adalah 6 tahun. Ratarata paparan whole body vibration yang diterima subyek sebesar $1,257 \mathrm{~m} / \mathrm{dt}^{2}$ dan serta paparan whole body vibration yang paling tinggi diterima responden sebesar 2,605 m/dt² serta paling rendah 0,612 $\mathrm{m} / \mathrm{dt}^{2}$. Rata-rata subyek menggunakan bis dengan merek Mitsubishi 17 orang $(65,4 \%)$, Daihatsu 4 orang $(15,4 \%)$ dan Isuzu 5 orang $(19,2 \%)$.

3. Ketajaman Penglihatan Mata Kanan dan Kiri Pengemudi Bis Po Nikko Putra Yogyakarta

Rata-rata ketajaman penglihatan mata kanan subyek penelitian sebesar 1,63 dan rata-rata ketajaman penglihatan mata kiri 1,54. Rata-rata ketajaman penglihatan mata kanan dan kiri responden ternyata tidak mengalami perbedaan, serta membuktikan bahwa sebanyak 24 pengemudi (92,3\%) untuk tajam penglihatan mata kanan dapat dikatakan normal dan tidak normal 2 pengemudi $(7,7 \%)$, begitu juga dengan ketajaman penglihatan mata kanan sebanyak 23 pengemudi $(88,4 \%)$ normal dan 3 pengemudi $(11,6 \%)$ tidak normal.

\section{Kondisi Lingkungan Kerja}

Rata-rata armada bis yang dimiliki PO Nikko Putra Yogyakarta telah berumur tua dan kondisinya kurang baik sehingga mempunyai getaran mekanis yang tinggi. Fasilitas bis serba terbatas dan kapasitasnya memuat penumpang sekitar 15 orang (termasuk bis mini). Kondisi interior bis yang kurang baik dan keadaan tempat duduk pengemudi yang terbuat dari bantalan busa yang dibungkus dengan kalep kulit imitasi, model tempat duduk, pijakan kaki dan setir bis yang tidak ergonomis sehingga dirasa tidak nyaman, serta pencahayaan tempat kerja dengan bantuan pencahayaan sinar matahari.

\section{Waktu Kerja Sehari Pengemudi}

Waktu kerja subyek penelitian dalam satu hari tidak menentu, tergantung dari jumlah penumpang. Akan tetapi rata-rata pengemudi PO Nikko Putra jam kerjanya dari jam 06.00 WIB sampai dengan 18.00 WIB dengan istirahat hanya satu jam, berarti dalam sehari pengemudi berkerja selama 11 jam. Keadaan ini telah melebihi waktu kerja yang telah ditetapkan oleh Peraturan Pemerintah Republik Indonesia nomor 44 tahun 1993 tentang Kendaraan dan Pengemudi, yang menyatakan bahwa lama kerja bagi seorang pengemudi kendaraan umum adalah 8 jam sehari. Pengemudi yang telah mengemudikan kendaraannya 
selama 4 jam berturut-turut harus diberikan istirahat sekurang-kurangnya setengah jam. ${ }^{7}$

\section{E. Ketajaman penglihatan pada profesi pengemudi}

Seorang calon pengemudi sebelum mengemudikan dan berprofesi menjadi seorang pengemudi bis harus melalui syarat-syarat yang wajib dipenuhi. Peraturan Pemerintah No. 44 Tahun 1993 menyatakan tentang Kendaraan dan Pengemudi, pengemudi adalah orang yang mengemudikan kendaraan. Surat izin mengemudi diberikan kepada orang yang namanya tertera di dalamnya sesuai dengan ketentuan peraturan perundang-undangan yang berlaku, dan merupakan tanda bukti kecakapan dan keabsahan pengemudi untuk mengemudikan kendaraan bermotor di jalan dan dapat pula digunakan sebagai identitas pengemudi. $^{7}$

Sutarjo $(1999)^{8}$, menyatakan bahwa seorang pengemudi harus memenuhi beberapa syarat agar dapat mengemudi dengan selamat. Seperti tajam penglihatan minimal 0,50 pada satu mata dan 0,20 pada mata lainya, lapang pandang minimal $45^{\circ}$ di segala meridian, dan mampu membedakan warna merah, hijau dan kuning. Berdasarkan hasil pengukuran ketajaman penglihatan pengemudi menunjukkan bahwa semua pengemudi PO Nikko Putra terkecuali satu pengemudi, memenuhi syarat ketajaman penglihatan seorang pengemudi.

\section{F. Paparan Whole Body Vibration yang Diterima Pengemuid dalam Sehari}

Hasil analisis deskriptif menunjukkan tingkat rata-rata paparan whole body vibration yang diterima oleh pengemudi PO Nikko Putra Yogyakarta dapat dilihat dari grafik berikut ini:

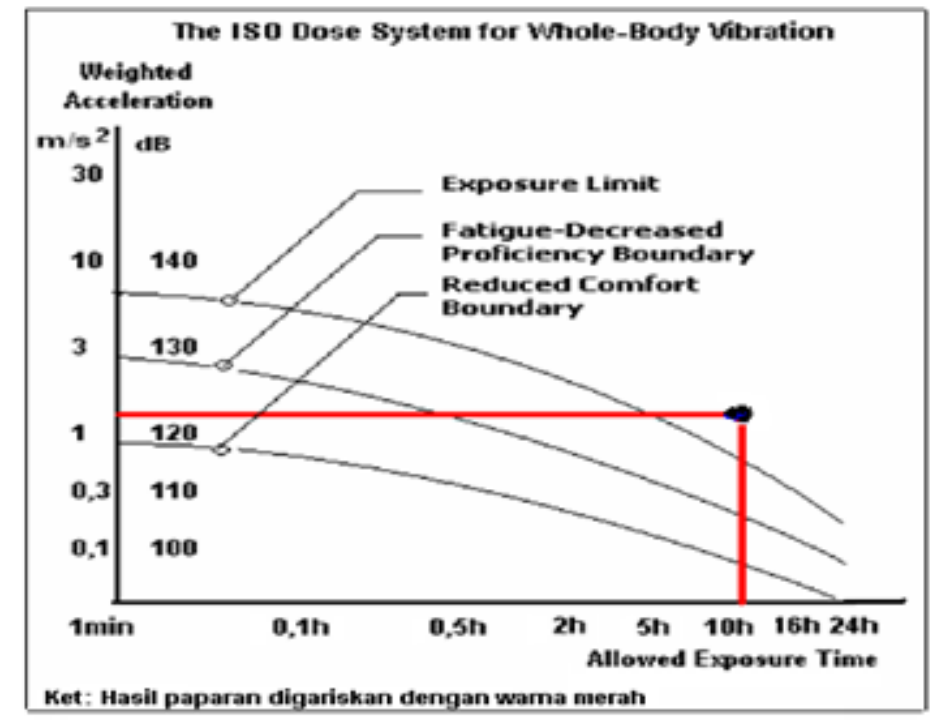

Sumber: ISO 2631, 1997

Gambar 1. Paparan Whole Body Vibration yang Diterima Pengemudi Bis PO Nikko Putra Yogyakarta Dalam Sehari

Gambar 1 menunjukkan bahwa getaran whole body vibration yang diterima pengemudi sebesar $1,257 \mathrm{~m} / \mathrm{dt}^{2}$ dengan frekuensi $50 \mathrm{~Hz}$ dalam satu hari selama 11 jam termasuk dalam kategori melebihi nilai ambang batas (exposure limit)

KES MAS Vol. 5, No. 3, September 2011: 162-232 
yang dapat mengganggu kesehatan pekerja. Besaran akselerasi getaran tersebut telah melampaui batas yang telah ditetapkan oleh ISO 2631. Oleh karena itu faktor fisik lingkungan kerja yang diterima pengemudi harus segera dikurangi dan dikendalikan.

Standar tingkat getaran whole body vibration terhadapat kenyamanan bekerja yang berlaku di tingkat internasional mengacu pada ISO 2361 tentang getaran untuk kenyamanan pekerja, dengan klasifikasi sebagai berikut:
1) Kurang dari $0,315 \mathrm{~m} / \mathrm{dt}^{2}$
: nyaman.
2) $0,315-0,630 \mathrm{~m} / \mathrm{dt}^{2}$
: sedikit kurang nyaman.
3) $0,630-1,000 \mathrm{~m} / \mathrm{dt}^{2}$
4) $1,000-1,600 \mathrm{~m} / \mathrm{dt}^{2}$
: agak tidak nyaman.
5) $1,600-2,000 \mathrm{~m} / \mathrm{dt}^{2}$
: tidak nyaman.
6) Lebih dari $2,000 \mathrm{~m} / \mathrm{dt}^{2}$
: sangat tidak nyaman.
: sangat tidak nyaman ekstrim.

Di Indonesia, Nilai Ambang Batas paparan whole body vibration untuk kesehatan dan kenyaman bagi pekerja belum diatur oleh Keputusan Menteri Tenaga Kerja nomor 51 tahun 1999 tentang Nilai Ambang Batas Faktor-faktor Fisik di Tempat Kerja. Pada peraturan tersebut hanya mengatur Nilai Ambang Batas paparan lokal atau hand arm vibration (getaran tangan dan lengan). ${ }^{2}$

Besarnya getaran mekanis bis PO Nikko Putra Yogyakarta dikarenakan dari faktor umur bis yang rata-rata berumur 19 tahun sehingga mesin bis menghasilkan getaran yang tinggi ditambah lagi kurang baiknya sistem perawatan bis. Berdasarkan hasil wawancara dengan pengemudi, bahwa penggantian oli dilakukan paling cepat sebulan sekali dan servis mesin dilakukan hanya jika terjadi kerusakan.

\section{G. Hubungan Paparan Whole Body Vibration dengan Penurunan Ketajaman Penglihatan}

Tabel 1. Korelasi Koefesien Pearson Antara Paparan Whole Body Vibration dengan Penurunan Ketajaman Penglihatan Bis PO Nikko Putra Yogyakarta

\begin{tabular}{cccc}
\hline Variabel & Simbol & \multicolumn{2}{c}{ KetajamanPenglihatan } \\
\cline { 2 - 4 } & & Kanan & Kiri \\
\hline Paparan Whole & Pearson & $-0,005$ & 0,110 \\
Body Vibration & Corelation & & \\
\hline & Sig & 0,981 & 0,592 \\
\hline
\end{tabular}

Tabel 1 menunjukkan hasil analisis korelasi Pearson whole body vibration dengan ketajaman mata sebelah kanan sebesar $-0,005$ dan nilai probabilitasnya 0,981 sehinga Ho diterima karena nilai probabilitasnya $>0,05$. Kesimpulannya $\mathrm{Ha}$ ditolak, jadi tidak terdapat hubungan whole body vibration dengan ketajaman mata sebelah kanan. Pada mata sebelah kiri sebesar 0,110 dengan nilai 0,592, sehingga Ho diterima karena nilai probabilitasnya $>0,05$. Kesimpulannya $\mathrm{Ha}$ ditolak, jadi tidak terdapat hubungan whole body vibration dengan ketajaman mata sebelah kiri.

Whole body vibration yang berasal dari getaran mekanis mesin bis memapari tubuh pengemudi bis PO Nikko Putra Yogyakarta melalui tempat duduk dan 
pijakan kaki. Suma'mur $(1988)^{4}$ menyatakan getaran yang terjadi pada bis mempunyai pengaruh yang bersifat mekanis, sebenarnya hanya getaran dari tempat duduk dan topangan kaki yang penting, karena diteruskan kebadan. Sebagian besar dari kekuatan mekanis mesin dipaparkan ke tubuh pekerja dalam bentuk getaran mekanis. Berbeda dengan getaran udara yang pengaruhnya adalah akustik, getaran mekanis berakibat timbulnya resonansi dari organ-organ tubuh, sehingga pengaruhnya bersifat mekanis yang efeknya dapat merusak selsel jaringan tubuh dan mengganggu metabolisme tubuh manusia.

Biomekanis tubuh manusia mempunyai frekuensi normal yang berbeda-beda, Brauer (1989) $)^{9}$ menyatakan bahwa tangan manusia memiliki frekuensi rerata 50 $200 \mathrm{~Hz}$, perut yang memiliki frekuensi rerata $4-8 \mathrm{~Hz}$, kepala memiliki frekuensi rata $25 \mathrm{~Hz}$ sedangkan Malerbi $(1989)^{10}$ menyatakan mata memiliki frekuensi sekitar 30-80 Hz. Suma'mur (1988) ${ }^{4}$ menyatakan dari semua organ tubuh manusia yang mudah dan rentan terpapar whole body vibration adalah mata karena pada frekuensi $4 \mathrm{~Hz}$ mata manusia dapat mengikuti getaran yang diterima akan tetapi jika getaran melebihi frekuensi tersebut maka mata akan mengalami gangguan. Getaran dalam cakupan frekuensi resonansi melebihi frekuensi normal mata dapat mengganggu tugas penglihatan dan merusak kekuatan retina atau mengganggu saraf yang menghubungkan mata. ${ }^{9}$

Banyak hal yang dapat mempengaruhi paparan whole body vibration yang diterima oleh pengemudi bis. Suma'mur $(1988)^{4}$ ada banyak faktor yang dapat mempengaruhi besar kecilnya paparan whole body vibration yang diterima oleh operator yang bekerja pada alat transportasi terutama pada transportasi berupa bis seperti kondisi tempat duduk dan keadaan kondisi ban.

Pekerjaan mengemudikan bis merupakan salah satu pekerjaan yang monoton karena mayoritas aktifitasnya hanya duduk dan menggerakkan kaki dan tangan dan memfokuskan mata untuk melihat semua kegiatan yang berada di jalan raya. Pekerjaan ini dapat menjadikan seorang pengemudi merasa bosan dan cepat mengalami kelelahan, terutama pada bagian organ mata yang harus selalu berakomodasi secara penuh dalam waktu yang lama.

Pengemudi bis yang dalam pekerjaan selalu memfokuskan akomodasi dengan sedikit waktu untuk mata beristirahat dan keadaan ini berlangsung hingga perpuluh-puluh tahun, akibatnya akan dapat melemahakan otot saraf mata sehingga dapat membuat mata mudah mengalami kelelahan dan dapat menurunkan ketajaman penglihatan pengemudi. Ditambah lagi dengan faktor kondisi lingkungan berupa getaran mekanis mesin bis yang akan mepercepat terjadinya penurunan ketajaman penglihatan. Malerby $(1989)^{10}$, whole body vibration telah dilaporkan menjadikan pusing, sakit kepala, mual-mual, kerusakan tulang belakang, varicose pembuluh darah, pandangan kabur, kerusakan paruparu, pendarahan berkenaan dengan dubur, haematuria, penurunan berat beban, dan kegagalan hati. Masing-masing efek ini dihubungkan dengan getaran pada frekuensi tertentu.

Hasil analisis korelasi paparan whole body vibration dengan penurunan ketajaman penglihatan, menunjukkan tidak adanya hubungan. Hal ini dimungkinkan karena mata pengemudi selalu berakomodasi secara penuh pada saat mengemudi dan ditambah lagi dengan faktor lingkungan kerja berupa paparan whole body vibration yang mempengaruhi gerakan bola mata sehingga dampaknya hanya menimbulkan kelelahan mata setelah mengemudikan bis selama seharian.

Penelitian ini menggunakan rancangan cross sectional, Murti (1996) ${ }^{5}$ cross sectional merupakan rancangan penelitian yang paling efesien untuk 
merumuskan hipotesis baru, tetapi lebih lemah untuk pengujian hipotesis kausal jika dibandingkan dengan rancangan cohort dan case control. Ditambah lagi pada penelitian ini besar sampel hanya 26 pengemudi, dianggap terlalu kecil. Oleh karena itu, hasil dari penelitian ini tidak maksimal sehingga tidak ada hubungan paparan whole body vibration yang diterima pengemudi bis PO Nikko Putra Yogyakarta dengan penurunan ketajaman penglihatan. Sebaiknya untuk penelitian selanjutnya mengunakan sampel yang lebih besar dan atau menggunakan rancangan cohort.

\section{H. Hubungan Masa Kerja dengan Penurunan Ketajaman Penglihatan}

Tabel 2. Korelasi Koefesien Pearson Masa Kerja dengan Penurunan Ketajaman Penglihatan Pengemudi Bis Po Nikko Putra Yogyakarta

\begin{tabular}{cccc}
\hline Variabel & Simbol & \multicolumn{2}{c}{ Ketajaman Penglihatan } \\
\cline { 3 - 4 } & & Kanan & Kiri \\
\hline Masa Kerja & $\begin{array}{c}\text { Pearson } \\
\text { Corelation }\end{array}$ & $-0,077$ & 0,003 \\
\hline & Sig & 0,709 & 0,990 \\
\hline
\end{tabular}

Tabel 2 menunjukkan hasil analisis korelasi Pearson masa kerja dengan ketajaman mata sebelah kanan sebesar - 0,077 dan nilai probabilitasnya 0,709 sehinga Ho diterima karena nilai probabilitasnya $>0,05$. Kesimpulannya $\mathrm{Ha}$ ditolak, jadi tidak terdapat hubungan masa kerja dengan ketajaman mata sebelah kanan. Pada mata sebelah kiri sebesar 0,003 dengan nilai probabilitasnya 0,990, sehingga Ho diterima karena nilai probabilitasnya $>0,05$. Kesimpulannya $\mathrm{Ha}$ ditolak, jadi tidak terdapat hubungan masa kerja dengan ketajaman mata sebelah kiri.

Mata merupakan panca indera yang fungsinya untuk melihat dan juga merupakan organ tubuh kita yang sangat penting serta sangat peka terhadap pengaruh lingkungan sekitar. Mata harus selalu dijaga agar tetap selamat, sehat dan selalu memperoleh kesempatan mendapatkan citra luar yang menyenangkan demi tetap terjaganya produktivitas yang memadai. ${ }^{11}$ Sherwood $(2001)^{12}$ menyatakan bahwa ketajaman penglihatan adalah kemampuan untuk membedakan dua titik yang terletak berdekatan. Ketajaman penglihatan didefinisikan sebagai kemampuan mata untuk dapat melihat suatu objek secara jelas dan sangat tergantung pada kemampuan akomodasi mata.

Pengemudi bis selalu memfokuskan matanya dan bekerja penuh konsentrasi agar dapat menjalankan armada bisnya dengan lancar dan selamat. Tanggung jawab seorang pengemudi sangatlah besar terhadap dirinya sendiri dan penumpang yang harus dijamin keselamatannya sampai tempat tujuan. Oleh karena itu, kondisi kesehatan baik fisik dan mental pengemudi harus tetap dijaga.

Hasil pemeriksaan ketajaman penglihatan 26 pengemudi bis PO Nikko Putra Yogyakarta menunjukkan bahwa rata-rata ketajaman penglihatan mata kanan pengemudi sebesar 1,63 dan rata-rata ketajaman penglihatan mata kiri pengemudi 1,54 dan rerata ketajaman penglihatan mata kanan dan kiri pengemudi ternyata tidak mengalami perbedaan yang begitu terlalu jauh hanya 0,09 . Penelitian ini juga menunjukkan sebanyak 24 pengemudi $(92,3 \%)$ untuk 
tajam penglihatan mata kanan dapat dikatakan normal dan tidak normal 2 pengemudi $(7,7 \%)$, begitu juga dengan ketajaman penglihatan mata kanan sebanyak 23 pengemudi $(88,4 \%)$ normal dan 3 pengemudi $(11,6 \%)$ tidak normal.

Ketika orang menjadi lebih tua, lensanya kehilangan sifat elastis dan menjadi suatu massa relatif keras, dikarenakan denaturasi protein secara progresif. Oleh karena itu, kemampuan untuk mengambil suatu bentuk sferis secara progresif berkurang, daya akomodasi menurun dari kira-kira 14 dioptri segera setelah lahir menjadi kira-kira 2 dioptri pada usia 45 sampai 50 . sesudah itu mata dapat dianggap hampir sama sekali tidak berakomodasi, keadaan ini dikenal sebagai presbiopia. ${ }^{6}$ Suma'mur $(1988)^{4}$ menyatakan bahwa ketajaman penglihatan normal jarang sekali ditemukan pada pekerja yang berumur diatas 40 tahun. Oleh karena itu, pada hasil ketajaman penglihatan pengemudi dalam penelitian ini yang berumur 40 tahun mayoritas mempunyai ketajaman penglihatan normal.

llyas $(2002)^{13}$ menyatakan mata dapat dikatakan normal bila ketajaman penglihatan antara 2,00 sampai 0,80 sedangkan berdasarkan hasil penelitian mayoritas responden ketajaman penglihatannya normal. Untuk dapat melihat benda dengan jelas, mata harus melakukan akomodasi, mencembungkan atau memipihkan lensa. Makin tua umur manusia, kekuatan mengakomodasi mata biasanya makin berkurang, titik dekatnya akan menjauh dan untuk mendekatkanya memerlukan kaca mata. Kadar cahaya ikut mempengaruhi proses akomodasi. Semakin kurang kadar cahaya, makin kurang pula kecepatan dan ketepatan akomodasi. ${ }^{11}$ Ganong $(1983)^{14}$ menjelaskan bahwa mata akan mengalami penurunan ketajaman jika mata berakomodasi terhadap obyek pada jarak yang berbeda-beda dan secara terus-menerus dalam tenggang waktu yang lama.

Hasil analisis korelasi masa kerja dengan penurunan ketajaman penglihatan pengemudi, menunjukkan tidak adanya hubungan. Peneliti berasumsi bahwa pengaruh paparan whole body vibration terhadap penurunan ketajaman penglihatan pengemudi memerlukan waktu yang sangat lama dan dikuatkan oleh penelitian sebelumnya yang dilakukan Rusdjijati $(2005)^{15}$ yang menunjukkan bahwa tidak adanya pengaruh paparan getaran tempat duduk dan lama kerja terhadap kelelahan kerja, walaupun paparan getaran yang diterima pengemudi di atas $2 \mathrm{~m} / \mathrm{dt}^{2}$ (kategori sangat tidak nyaman yang ektrim) melebihi nilai ambang batas yang telah ditetapkan ISO 2361 dan Hidayat $(2002)^{16}$ yang menunjukkan tidak adanya hubungan antara tingkat pencahayaan dengan penurunan ketajaman penglihatan pekerja pengrajin perak. Walaupun secara teori faktor pencahayaan pada tempat kerja mempunyai pengaruh yang sangat besar terhadap penurunan ketajaman penglihatan pekerja dibandingkan pengaruh paparan whole body vibration.

\section{Pengendalian Paparan Whole Body Vibration}

Mengenal dan memahami berbagai aspek penyakit akibat kerja sebagai salah satu risiko akibat pekerjaan atau lingkungan kerja, merupakan langkah awal guna meminimalisasi akibat yang tidak dikehendaki. Sikap menunggu atau membiarkan seorang pekerja menderita penyakit akibat kerja, jelas merupakan tindakan yang sangat merugikan $\square$ (Budiono, 2003a). ${ }^{17}$

Habsari $(2003)^{18}$ pengendalian yang perlu dilakukan untuk mengurangi paparan getaran mekanis bis dengan cara pengendalian teknis seperti: 1) memelihara mesin bis dengan baik, selalu mengganti bagian-bagian mesin yang rusak dan pemberian pelumas yang teratur; 2) perlu diperhatikan juga kondisi bis seperti ban harus dipompa dengan baik; 3) menggunakan alat penahan 
goncangan shock) suspensi yang standar sehingga dapat mengurangi getaran mekanis bis; 4) sedangkan bentuk penyediaan Alat Pelindung Diri berupa modifikasi bentuk tempat duduk pengemudi yang berfungsi juga untuk mengurangi paparan whole body vibration dirasa sangat dibutuhkan akan tetapi untuk memenuhinya memerlukan biaya yang sangat besar karena harus mendesain ulang bentuk tempat duduk dan menggunakan peredam berupa bantalan yang tebal; 5) membuat kartu pemeriksaan atau laporan rutin tentang kondisi bis tiap bulan sehingga dapat dipakai untuk pemeliharaan bis berkala. Hal tersebut dapat dihindari kecelakaan dan penyakit akibat kerja serta meningkatkan produktivitas kerja sehinga pekerja dapat melakukan aktivitasnya dalam keadaan selamat dan sehat.

\section{SIMPULAN DAN SARAN}

\section{A. Simpulan}

1) Paparan whole body vibration yang diterima pengemudi yang berasal dari getaran mekanis mesin bis sebesar $1,257 \mathrm{~m} / \mathrm{dt}^{2}$, menurut ISO 2631 termasuk dalam kategori exposure limit.

2) Tidak ada hubungan (mata kanan $p$ 0,981 dan mata kiri $p$ 0,592) antara paparan whole body vibration dengan penurunan ketajaman penglihatan pengemudi.

3) Tidak ada hubungan (mata kanan $p 0,709$ dan mata kiri $p$ 0,990) antara masa kerja dengan penurunan ketajaman penglihatan pengemudi.

\section{B. Saran}

1) Bagi Dinas Perhubungan Kota Yogyakarta

Perlu ada pengaturan tambahan tentang pemeriksaan getaran mekanis bis dalam pemeriksaan kelayakan kendaraan.

2) Bagi Pimpinan PO Nikko Putra Yogyakarta

Diharapkan dapat melakukan himbauan kepada para pengusaha untuk meningkatkan perawatan bis secara rutin dan memperhatikan kondisi ban bis sebagai prioritas utama untuk segera dibenahi selanjutnya memperhatikan kondisi tempat duduk dan sistem suspensi agar dapat mengurangi paparan whole body vibration serta mengurangi lama kerja pengemudi menjadi 8 jam/ hari.

3) Bagi Pengemudi PO Nikko Putra Yogyakarta

Agar selalu memperhatikan kondisi kesehatan fisik dan mentalnya agar dapat melaksanakan tugas dengan baik serta juga memperhatikan keselamatan dirinya dan penumpang.

4) Bagi Peneliti Lain

Perlu dilakukan penelitian tentang pengaruh paparan whole body vibration terhadap penurunan ketajaman penglihatan dan lapang pandang mata pengemudi dengan menggunakan rancangan penelitian cohort dan sampel yang lebih besar. 


\section{DAFTAR PUSTAKA}

1. Subair, M. $\square$ tanpa tahun $\square \square$ Reformasi Sistem Transportasi Umum Sebagai Upaya Peningkatan Keselamatan Lalu Lintas dan Angkutan Jalan. Terdapat dalam http:// bair.web.ugm.ac.id/content/transportasi, diakses tanggal 7 Mei 2007.

2. Departemen Tenaga Kerja RI. 1999. Nilai Ambang Batas Faktor Fisik di Tempat Kerja, Keputusan Menteri Tenaga Kerja. Jakarta.

3. Joubert, D. 2001. Whole Body Vibration. Australia: Central Queensland University terapat dalam http://www.cdc.gov/niosh/pot_set1.html diakses tanggal 2 Mei 2007.

4. Suma'mur P.K. 1988. Higene Perusahaan dan Kesehatan Kerja. Jakarta: CV Haji Masagung.

5. Murti, B. 2003. Prinsip dan Metode Riset Epidemiologi. Yogyakarta: Gadjah Mada University Press.

6. Guyton, A. 1990. Fisiologi Manusia dan Mekanisme Penyakit. Terjemahan Petrus Adrianto. Jakarta: Buku Penerbit Kedokteran EGC.

7. Departemen Perhubungan RI. 1993. Kendaraan dan Pengemudi, Peraturan Pemerintah. Jakarta.

8. Sutarjo. 1999. Penyakit Mata Okupasional. Seminar Sehari Deteksi dan Manajemen Penyakit Okupasional. 5 Juli 1999. Yogyakarta: Pusat Penelitian dan Pengembangan Ilmu Kesehatan Masyarakat, Universitas Gadjah Mada, bekerja sama dengan Program Studi Ilmu Kesehatan Kerja.

9. Brauer, R.L. 1990. Safety and Health for Engineer. New York: Van Nostrand Reinhold.

10. Malerbi, M. 1989. Vibration. Occupational Health Practice. Editor: Waldron, H.A. London: Butterworths and Co Publishers Ltd.

11. Sedarmayanti. 1996. Tata Kerja dan Produktivitas Kerja. Bandung: Penerbit Mandar Maju.

12. Sherwood, L. 2001. Fisiologi Manusia dari Sel ke Sistem. Terjemahan Brahm Pendit. Jakarta: Penerbit Buku Kedokteran EGC.

13. llyas, S. 2002. IImu Penyakit Mata. Jakarta: Balai Penerbit Fakultas Kedokteran Universitas Indonesia.

14. Ganong, W.F. 1998. Buku Ajar Fisiologi Kedokteran. Jakarta: Buku Penerbit Kedokteran EGC.

15. Rusdjijati, R. 2005. Pengaruh Paparan Getaran Tempat Duduk dan Lama Kerja

16. Hidayat, N. 2002. Hubungan Antara Tingkat Pencahayaan dan Posisi Kerja dengan Ketajaman Penglihatan Pengrajin Perak di Kota Gede Yogyakarta. Tesis. Yogyakarta: Program Pascasarjana Universitas Gadjah Mada.

17. Budiono, A.M. 2003a. Beberapa Penyakit Akibat Kerja Karena Pengaruh Bahan

18. Habsari, N.D. 2003. Aspek Penerangan, Kebisingan dan Getaran di Tempat Kerja dan Pengendaliannya, Bunga Rampai Hyperkes dan Kesehatan Kerja. Editor: Jusuf, R.M., Pusparini, A. dan Budiono, A.M. Semarang: Badan Penerbit Universitas Diponegoro, halaman $31-36$. 